\title{
Students as Vital Participants in Research Projects
}

\author{
PATTY W LIDDELL, RITA M HEUERTZ
}

\begin{abstract}
Inclusion of research coursework into a medical technology or clinical laboratory science program is currently viewed as a mark of a good degree program. Examples of this type of coursework are evaluation of scientific papers, techniques of scientific writing, application and performance of statistical analysis and introduction to research ethics (e.g., Institutional Review Board approval process). While many programs have the ability to recruit experienced scientists into research mentorship of medical technology/clinical laboratory science students, it is recognized that not all programs have this ability. It is also recognized that clinical laboratorians are performing critical diagnostic tests and, in this capacity, have the ability to identify research projects that are necessary, evidence-based and timely. It is hereby proposed that clinical laboratorians take advantage of this innate ability and create rich teaching experiences for students by including them in performance of research projects. Because of the fact that students are armed with up-to-date knowledge, have willing and enthusiastic spirits and are highly motivated to learn, they are vital participants in research. The students receive an invaluable active learning experience and possibly a future job; the clinical laboratorians meet and possibly exceed the research and scholarship expectations of their institutions; and the scientific community benefits by the science being shared through publication in scientific journals.
\end{abstract}

INDEX TERMS: student research, medical technology, clinical laboratory science

ABBREVIATIONS: ASCLS - American Society of Clinical Laboratory Science, CLS - Clinical Laboratory Science, CAP - College of American Pathologist, CLIA -Clinical Laboratory Improvement Amendments, DCLS - Doctorate in Clinical Laboratory Science

Clin Lab Sci 2011;24(2):66
Patty W. Liddell, MS, MT(ASCP)SH, Baptist College of Health Sciences, Memphis, TN

Rita M. Heuertz, PhD, MT(ASCP), Clinical Laboratory Science Department, Doisy College of Health Sciences, Saint Louis University, Saint Louis, MO

Address for Correspondence: Patty W. Liddell, MS, MT(ASCP)SH, Basic Science Labs, 1003 Monroe Avenue, Baptist College of Health Sciences, Memphis, TN, 38104

Most colleges, universities and clinical settings in the USA have faculty expectations of research and scholarship: in fact, many educational institutions and degree programs are currently rated by the research output of their faculty. ${ }^{1}$ Additionally, decisions such as promotion, tenure and salary sometimes are heavily based on research productivity. It has been stated that research and scholarly activities are crucial components in validation and advancement of the Clinical Laboratory Science (CLS) profession and research efforts of CLS faculty strengthen the practice of laboratory science and contribute new knowledge to the field. ${ }^{1}$ Increasingly more CLS faculty are seeking degrees beyond the BS and demographic results indicate the majority of CLS faculty contributing to research and scholarship have earned doctorates, hold the academic rank of professor, are tenured and are employed at 4year institutions of higher education. ${ }^{1}$ Attention has been drawn to the fact that the Association of School of Allied Health Professions advocates increased research activities among the allied health disciplines, including clinical laboratory science. ${ }^{2}$

Given the reality that the CLS professoriate is graying and that there is a documented CLS shortage, current circumstances call for advocacy and nurturance of future CLS faculty, particularly those with research interests and experience. ${ }^{2}$ While teaching and service are two tenets of successful faculty outcomes (e.g., 


\section{CLINICAL PRACTICE}

promotion, tenure), the third element of scholarship is an area of expertise that needs to be taught to CLS students. ${ }^{3}$ Future CLS practitioners and professors need to receive research mentoring so they will be successful in the "publish or perish" world. There has been interest stated to "grow our own" students able to be CLS professionals, practitioners and faculty serving in capacities of teaching, service and research/scholarship. ${ }^{3}$

Grooming CLS students in research is an important addition to the critical, analytical and interpretive skills currently taught. The research component better prepares CLS graduates for graduate schools, careers in pharmaceuticals and industry and professional degrees such as medicine and dentistry, all of which are career paths chosen by some CLS degree holders. In addition, development of research skills in undergraduate and graduate CLS students is a way to increase scholarliness and research confidence in clinical laboratorians of the future. ${ }^{1}$ It may be envisioned that the professional CLS doctorate (DCLS) will prepare its graduates to be the ones that provide evidence-based medicine in the practice of CLS since their focus will be on pre-analytic and post-analytic processes and the relevance of clinical laboratory information to medical effectiveness, costefficiency, utilization/interpretation, patient safety and reduced number of medical errors. ${ }^{4.5}$

We have been recently reminded that some tasks regularly performed in the clinical laboratory have research potential. An article by Mundt and Shanahan lists familiar tasks which generate information beneficial to other clinical laboratories. ${ }^{6}$ Additional tasks and/or projects have been identified in the literature ${ }^{7}$ as well as herein displayed (Table 1). A take-home point is that it is a CLS responsibility to publish information when it is of potential use to others.

Though many of us realize that information we generate may be of interest to other clinical laboratory scientists, it is clear that bench technologists are unlikely to attempt publication. Many if not most technologists feel far-removed from the "movers and shakers" in their fields and doubt their abilities to contribute significantly to the body of scientific knowledge. In addition, the CLS work environment frequently views publication as an academic endeavor and allows little to no time or incentive for this undertaking. Indeed, more so than ever in this current economic environment, clinical laboratories focus on attributes of efficiency and leanness and delay projects requiring research and development. Given the predicted and current CLS workforce shortage, ${ }^{3,8,9}$ the possibility exists that even more focused efficiency and leanness will become the norm. Indeed, efficient utilization of personnel and prohibition of performance of projects deemed nonessential is becoming a common work ethic.

Table 1. Examples of Clinical Research Projects

- Linearity and calibration verification checks on i-STAT1 as per CAP and CLIA regulations

- Novel microsphere flow cytometry assay

- Survey of hospital laboratories for use/misuse assessment of the International Normalized Ratio

- Utilization of multi-test chemistry panels in a Pediatric Cancer Hospital

- Platelet aggregation dispersal using the GPIIb-IIIa antagonist Afciximab

- Epstein-Barr virus master mix validation study using $A B I$ 7900 and 7500 sequence detection systems

- Evaluation of endocrinology turn-around time in a Pediatric Cancer Hospital

Given the fact there is increased onus on academic faculty to participate in research and scholarly activities, the focus also lies outside the realm of academe. Many CLS faculty in academic institutions perform their own research, forward CLS students on to hospital, medical or research faculty or utilize a combination of the two to be able to provide research experiences for their students. The best service we can provide our students is to offer them appropriate experiences to maintain their professional expertise, entice them to grow intellectually as life-long learners and introduce them to predicted professional occurrences they may encounter in their on-the-job settings. Important are changes occurring in health care itself. Team rather than physician rounding to see hospitalized patients, increased number of discipline-specific clinical doctorates (e.g., the DCLS) and interprofessional, evaluative assessment as a means of patient care are all directions currently being taken to better provide for the health care needs of this country. Indeed, the new health care plan of President Obama 


\section{CLINICAL PRACTICE}

has a major focus on health maintenance rather than continuation of unhealthy life habits and behaviors. In this light, health care as we know it is or will be undergoing major changes. It is our duty to do what we can to prepare our CLS graduates to be able to change with the times and one way to do this is to prepare and/or entice them to become life-long learners. Introducing our students to research experiences broadens their horizons in terms of creative, logical and cause-and-effect thinking. Research experiences may lead CLS graduates to seek advanced degrees (professional or basic science), design better diagnostic tests or determine means by which patient length-ofstay in hospitals may be decreased. Once challenged to think about science rather than simply memorize it, the students are better able to remain up-to-date with changes they encounter in health care and in their profession.

\section{Student Involvement}

For these reasons, it is wise for clinical laboratorians to realize that they need look no further than students in their Medical Technology programs to find willing and interested participants to initiate and/or perform necessary tasks for research projects. Since some Medical Technology programs are located on the campus of a university with a heavy research emphasis, these students have the opportunity to enter into basic science research or clinical laboratory settings. Faculty members of the Medical Technology/Clinical Laboratory Science programs at the University of Tennessee and Saint Louis University have included research into the required course curriculum. The data acquisition phase is two weeks to two months in length. Matching student strengths with proposed projects is one of the many jobs a research course director endeavors to accomplish. This task involves a delicate dance of keeping clients happy while at the same time providing each student with an achievable and worthy project. It has been our experience that projects placed on hold due to financial cutbacks or decreased numbers of research grant awards have been able to find new life in the hands of students in Medical Technology/Clinical Laboratory Science programs. These students are energetic, professionally enthusiastic, equipped with the scientific basics and motivated to show themselves as ready and able future employees.
For these reasons, we strongly advocate student involvement in research.

While there are occasional students who are not interested in, adept at or compliant with performing a research project, it has been our experience that most students eagerly accept the challenge. Frequently, they value the research experience and its outcomes. Many students are motivated by the research itself, local and/or national research competitions, showcases of their accomplishments, presentation of their research data and/or publication of their results. When mentored for the research experience, the students develop confidence as well as knowledge in research topic content, protection of subjects in research, statistical analysis, presentation skills and writing abilities. One hurdle we have had to work through is the ability to offer research experiences on a researchlimited budget. To overcome this potential obstacle, faculty members have identified low-cost yet highquality research projects, developed collaborative arrangements thereby sharing research costs or worked with clinical faculty to acquire necessary research supplies. Another problem encountered is that students usually do not perform a complete project in this short period of time (e.g., part of a single semester) and do not have a manuscript ready for journal submission by the end of the semester. Since many students have research experiences in the final semester of senior year, the interested student and faculty mentor must complete manuscript writing and submission after commencement which sometimes can be a challenge. Another item that frequently ends up being the responsibility of the faculty mentor is the completion of all Institutional Review Board responsibilities in a timely manner so that the student can perform the research project during the narrow window of time for project performance. While much of the responsibility and follow-up falls upon the faculty mentor, it is rewarding to see the students stay in touch with the faculty mentor during this continued time of research learning. Additionally, it is rewarding to see our graduates win research awards, have manuscripts accepted for publication and move into leadership roles in the profession. This indeed has been our observation of our research-motivated graduates! 


\section{CLINICAL PRACTICE}

On a more general note, it has been reported that undergraduate student involvement in research increases student retention in academics as well as increases numbers of students pursuing science, technology, education and mathematics disciplines and careers. ${ }^{10}$ Inculcation of enthusiasm is a key element in positive research outcomes and the earlier the undergraduate student is exposed to research, the better it is for the individual and the society. The individual student is more engaged in academics throughout the younger years and learns how to be an active and life-long learner, which ultimately benefits society. Of importance is the fact that students enrolled in undergraduate scientific disciplines today are the source of tomorrow's scientists. Indeed, the CLS students of today are the source of tomorrow's CLS professionals, DLCS practitioners and CLS professoriate. Identifying and capturing their scientific interest and curiosity is important and makes the thrill of scientific discovery a reality to them.

\section{Our Experience}

For one of our students, a local hospital needed to evaluate a new molecular assay at the same time the medical technology student needed a worthy graduatelevel research project. As it turned out, it was a perfect match and a mutually beneficial endeavor. The hospital received invaluable assistance in validation of an assay for detection of the Clostridium difficile tcdB gene and the student acquired an interesting research project that resulted in a thesis, a Masters level degree and a job. This student was hired in the molecular biology laboratory of this hospital and continues to collect data on pediatric samples using the assay he developed and validated. His work continues to benefit the patient, the institution and the product manufacturer.

It is these clinical laboratory types of activities that make challenging and interesting research projects for students. Important follow-up of data accumulation is publication of research results obtained. At this point, clinical or didactic medical technology faculty need to become integrally involved to assist the student in manuscript write-up, submission, address of reviewers' concerns and publication. This type of arrangement (clinical laboratorians working with students currently enrolled in medical technology programs under the purview of academic laboratorians) is a collaborative marriage of opportunity, motivation and incentive for all parties involved. Students have valuable research projects and opportunities to show themselves, clinical laboratorians offer clinical expertise and academic faculty provide research focus and guidance. In the end, all involved parties gain opportunities to publish which benefits the student (advanced degree potentials, job possibilities), the clinical laboratorians (use of validated diagnostic tests without delay or additional costs) and the medical technology instructors/academic faculty (scholarship, active research program, publications - all of which are requirements for institutional tenure).

Since it is not always easy to initially identify research projects, we have provided a listing of clinical projects that have served as useful research material for both student and mentoring institution (Table 1).

\section{Research Opportunities}

One advantage of being located on a university campus is the availability of researchers willing to mentor medical technology students. Because of these researchers willingness, we have placed our students in laboratories of basic scientists thereby providing the students with a glimpse of an arena that most medical technologists rarely, if ever, see. At graduation, the Sigma $\mathrm{Xi}$ award for excellence in student research recognized such a project. The research mentor is a professor in graduate molecular sciences with a special interest in studying the bacteriophage $\mathrm{Mu}$, a virus that infects E. coli. Our student enthusiastically accepted the opportunity to definitively identify specific genomic regions of the bacteriophage and had the opportunity to learn several classic molecular techniques including transformation, restriction digestion, cloning, primer design and sequence analysis. Needless to say, this was an invaluable experience for our student. Additionally, this ongoing basic science research project may provide opportunities for medical technology students and didactic instructors in our program to author publications outside of the clinical laboratory science realm. In the specific case cited above, an experienced author (the molecular sciences professor) will use results generated by an undergraduate student and medical technology instructors to publish a basic science manuscript upon completion of the project. 


\section{CLINICAL PRACTICE}

Again, since it is not always easy to initially identify research projects, we have provided a listing of basic science projects that have served as useful research material for both student and mentoring institution (Table 2).

Table 2. Examples of Basic Science Research Projects

- Identification of retinal antigens in Xenopus lavevis

- In vitro release of lipocalin-2 by human subcutaneous omental adipocytes and non-fat cells

- Viability of mouse macrophages and THP-1 cells exposed to endotoxin-treated titanium

- Comparison of tumor necrosis factor-alpha production by cells under various conditions

- Isolation of cytosol from intestinal cells of Sprague-Dawley rats

\section{Conclusion}

Whether your Medical Technology program incorporates research into the student learning experience or stops teaching at the point of research theory, statistics and scientific writing, know that these students learn invaluable lessons by receiving research experiences. While deciphering a research article or interpreting data obtained in research experiments can appear overwhelming, it is highly rewarding for both experienced scientist and research student. Providing students with the intellectual tools needed for research experiences serves these future technologists well. It is important to remember that the workplace continues to evolve, the acquisition of knowledge never stops and clinical laboratorians have the ability to offer research opportunities to these new technologists. Take advantage of their willingness and enthusiasm by involving them in clinical laboratory projects that need research attention.

\section{Acknowledgments}

Thanks are extended to Dr. Linda Pifer at the University of Tennessee for her efforts year after year as she provides valuable opportunities to students and mentors alike.

\section{REFERENCES}

1. Waller KV, Karni KR. Scholarly activities of the most productive CLS faculty and schools in the USA. Clin Lab Sci 2010;23:175-9.

2. Waller KV, Clutter JE, Karni KR. Research and scholarship of Clinical Laboratory Science faculty members. Clin Lab Sci 2010;23:3-32-3-38,

3. Rohde RE, Falleur DM, Redwine GD, Patterson TL. Growing our own: Teaching and doing research in CLS. Clin Lab Sci 2010;23:3-11-3-18.

4. Leibach EK. Evidence based practice in CLS education. Clin Lab Sci 2010;23:3-2.

5. Leibach EK, Russell BL. A typology of evidence based practice research heuristics for Clinical Laboratory Science curricula. Clin Lab Sci 2010;23:3-46-3-50.

6. Mundt L, Shanahan K. ASCLS members perceptions regarding research. Clin Lab Sci 2009;22:170-5.

7. Saleh SM and Hamed, KM. Preparing CLS professionals to be consumers and producers of research. Clin Lab Sci 2010;23:319-3-23.

8. Passiment E. Update on the laboratory workforce-shortage crises. MLO Med Lab Obs 2006;38:64-5.

9. http://www.ascp.org/MainMenu/AboutASCP/Newsroom/ NewsReleases/ASCP-Wage-and-Vacancy-Report.aspx

10. Russell SH, Hancock MP, McCullough J. Benefits of undergraduate research experiences. Science 2007;316:548-9. 